\title{
Co-Existence or Alliance? Psychological Assessment and Its Effects on Therapeutic Process Using Systemic Psychotherapy as an Example
}

\author{
Anna Pittermann ${ }^{1,2}$, Klaus D. Kubinger ${ }^{2}$ \\ ${ }^{1}$ Department of Surgery, Medical University of Vienna, Vienna, Austria; \\ ${ }^{2}$ Faculty of Psychology, University of Vienna, Vienna, Austria. \\ Email: anna.pittermann@akhwien.at \\ Received August 5 $5^{\text {th }}$, 2010; revised December 22 $2^{\text {nd }}, 2010$; accepted December $27^{\text {th }}, 2010$.
}

\begin{abstract}
Psychotherapists are still uncertain about what positive or negative effect psychological assessment might have on the process of psychotherapy. The aim of this study was to sum up the effects of psychological assessment on the therapeutic process in the systemic therapy of couples. The question of whether psychological assessment techniques enhances therapeutic progress and helps to achieve therapeutic goals, from the point of view of the clients, was investigated using randomized samples of clients in couples therapy. For this purpose, couples, who had signed up for systemic psychotherapy, were randomly placed in either a group with psychological assessment or one without. In addition to the continual monitoring of the subjective achievement of therapeutic goals, the perceived benefits of the results of the psychological assessment by the clients and therapists were also investigated. The investigation of 42 couples showed that therapeutic success, from the client's point of view, occurred sooner and was more stable when a psychological assessment was done in advance. In general, psychological assessment was seen in a more positive light by the couples than by the therapists.
\end{abstract}

Keywords: Psychological Assessment, Systemic Psychotherapy, Therapeutic Progress

\section{Psychotherapy and Psychological Assessment}

Despite the extensive literature on psychological assessment (Kubinger, 2003; Kubinger, 2006) and its application within psychotherapy (Cierpka, 2000, 2003; Fiegl \& Reznicek, 2000; Kubinger, 2006; Laireiter, 2000a) there is still great un- certainty among practicing psychotherapists about the use of psychological assessment within their work. In Austria clinicalpsychological assessment forms only a small part, if at all present, of what is taught as part of psychotherapy education (e.g. Training guidelines - Psychoanalysis; Austrian Psychotherapy Act; Training guidelines - Systemic Therapy), resulting in little engagement with this subject for those psychotherapists without additional clinical psychological or psychological training. Psychological assessment is, thematically and in terms of application, closely linked to psychotherapy. Many questions addressed by psychological assessment are also relevant to psychotherapeutic practice and some questions can only be answered with the aid of psychological assessment (Laireiter, 2005). Despite, or perhaps, because of this close and yet vague connection, most therapists have a very clear attitude towards psychological assessment. They have decided to either reject, endorse or simply ignore the option of employing it, while the need is not felt for either the gathering of findings about efficacy based on psychological assessment or for existing findings to be incorporated into therapy (Ludewig, 2005; Stieger, 1995). This attitude is seldom supported by thoroughly researched results or experience tested in practice. Most of these attitudes either stem from personal opinion or life experience, and not from the scrutiny of the particular theoretical concepts of as- sessment, or are based on a profound lack of information about how to employ psychological assessment. Control studies of the effects of psychological assessment within psychotherapeutic processes, whether fruitful or disruptive in nature, could not be found even in extensive research of literature. Assessment, as an information gathering process, and psychotherapy whether seen as a fruitful partnership or an enforced and not very harmonic relationship, are an "integral element of a circular process” (Scheib \& Wirsching, 1994, p. 169). In everyday practice the therapist always encounters psychological assessment anew; patients come to the therapist with diagnoses or results, the therapist creates a hypothesis based on information, evaluates their own work with the help of assessment techniques (Braun \& Regli, 2000; Laireiter, 2000b) and even sometimes employs these for therapeutic purposes (especially projective techniques such as the Enchanted Family (Kos \& Biermann, 2002), representational tests such as the Family System Test (Gehring, 1998), or circular questioning in the Subjective Family Image (Mattejat, 1994)), for further information about assessment tasks in psychotherapy, see (Laireiter, 2000c). Some assessment techniques even come unmistakably from a therapeutic background (such as Beckmann, Brähler and Richter’s Giessen Test (Beckmann, Brähler, \& Richter, 1983) psychoanalysis or the Family Board (Ludewig, 2000) systemic family therapy). There are, especially among the main systemic family therapy clientele, namely couples and families (in the widest definition of those words), a large number of techniques which concentrate on this target group and the most common problems that they bring to psychotherapy. These techniques include Couples Diagnosis with the Giessen test (Brähler \& Brähler, 1997), the Family Relations Indicator (Howells \& Lickorish, 1989), the 
Family Assessment Measure (Cierpka \& Frevert, 1994), the Family System Test (Gehring, 1998) and the Family Identification Test (Remschmidt \& Mattejat, 1999) (see also Ludewig, 2000; Brähler \& Brähler, 1997; Benninghoven, Cierpka and Thomas, 2003; Thomas, 2003). Despite this wide range of test instruments many therapists would rather rely on their own diagnostic aptitude than an assessment procedure or gathering more information. The aim of this study is to investigate whether the therapeutic process in systemic family therapy is positively or negatively influenced by psychological assessment. A positive influence could be a focusing of the therapy process based on the results of an assessment done prior to therapy.

Psychological assessment could in this way simplify therapeutic work for the therapist, accelerate the achievement of therapeutic goals or lead to greater client satisfaction. However, it is also conceivable that this type of assessment has no influence, or even has a disruptive influence on the therapeutic process because it requires resources such as time and energy without providing any advantage to the therapeutic process. Furthermore, it might be subjectively experienced by the client as unhelpful or labeling.

\section{Trial Plan and Methods}

The study of the effects of psychological assessment on systemic couples therapy was carried out at the Institut für Eheund Familientherapie (IEF; Family Therapy Institute), Vienna. The IEF is a Vienna Social Services institute which currently employs nine systemic psychotherapists. The Family Therapy Institute provides systemic psychotherapy for couples, families and individuals. Psychological assessment is not routinely carried out there. The management team, therapeutic team and administrative team have all already kindly agreed to take part in the study, and to support the research project.

The plan for the study was to include couples who contacted the institute with "partnership problems" (as opposed to difficulties relating to other members of the family group). The randomization of couples was carried out by using the date that they joined the study. The couples were alternately placed in the "therapy without psychological assessment (PA)" (control group, CG) and the "therapy with psychological assessment" (trial group, TG). The trial group couples underwent psychological assessment lasting approximately one hour before the first session with the therapist (see Figure 1). In accordance with Orlinsky (2008) no attention was paid to the therapeutic variables (gender, age, number of years at IEF etc.) as it is in any case unclear as to how these effect the therapeutic process.

During the first four sessions, the clients from both groups were continually monitored by gathering information about their experience of the therapeutic progress. The number of sessions chosen for observation was based on the experience of the Family Therapy Institute, which showed that most therapeutic change happened within the first four sessions and that it was very possible to form an opinion on the success of the therapy at this point. Moreover, due to the numerous short courses of therapy that are carried out at the Family Therapy Institute, and for comparison and cost reasons, it seemed most logical to document the first four sessions. The documentation carried out by the therapist at the end of each session included the therapist's subjective appraisal of the degree of achievement of goals on a scale of 1 to 10 ( $1=$ no achievement; $10=$ maximum achievement of therapeutic goals), the documenting of the therapeutic process (routine electronic documentation of content of the session) and, if necessary, the documenting of any early termination or other therapeutic change. At the end of the session the couples were asked to separately mark their evaluation of the therapeutic progress on a scale of 1 to $10(1=$ no progress; $10=$ maximum progress). Additionally, after the fourth session the clients of the "with psychological assessment” group were asked for their feelings about psychological assessment and whether they would judge the instruments used to be helpful or interesting, or not. After the fourth session the therapists with clients of the "with assessment" group also received a questionnaire about how they, in retrospect, would evaluate the information obtained by psychological assessment. At the end of the four sessions of the study all the clients and therapists completed a final questionnaire regarding the achievement of the therapeutic goals.

\section{Test Condition “With Psychological Assessment”}

After initial contact with the Family Therapy Institute the subjects under the test condition "with psychological assessment” completed an assessment session lasting approximately one hour, during which they were presented with two relationship assessment questionnaires to work through. Every couple was separated so that each partner worked alone on the couples assessment with the Giessen Test (Brähler \& Brähler, 1997) and the questionnaire about supply and demand in partnerships ([Fragebogen zu Angebot und Nachfrage] FAN (Pfundner,

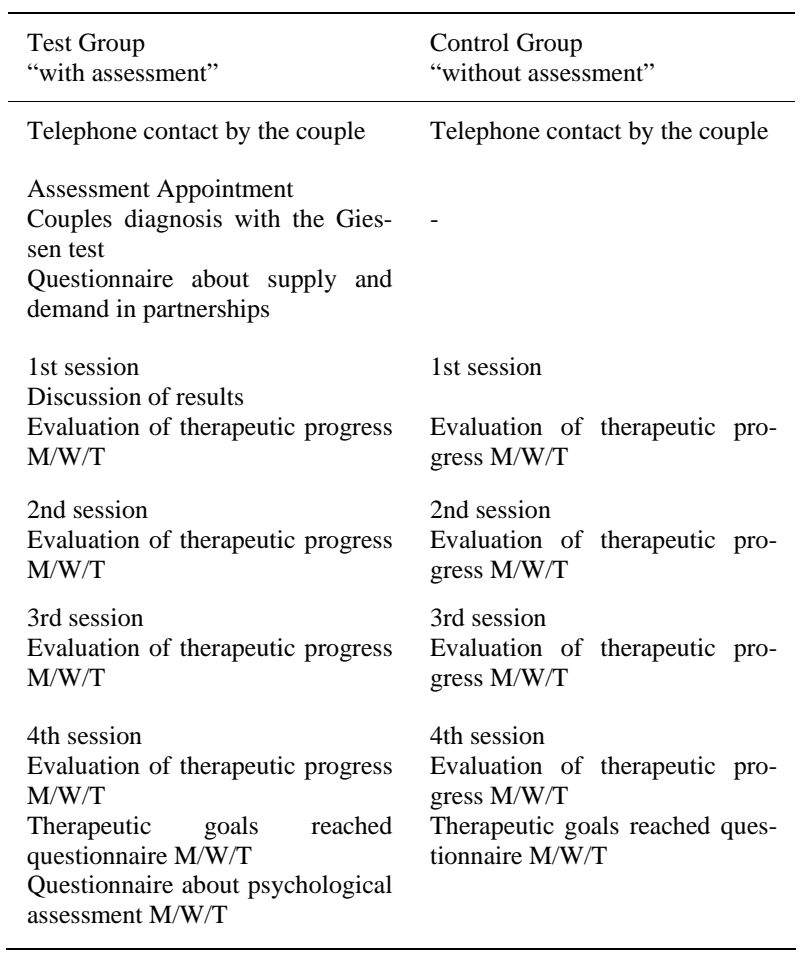

Figure 1.

Table representing the planned study $(M / W / T=$ conducted by Man/ Woman/Therapist). 
1997; Simader-Hunek, 2004; Kubinger, 2007).

\section{Couples Assessment with the Giessen Test}

Couples assessment with the Giessen test comprises of two questionnaires for each partner. Using the 40 items of the Giessen test, each partner first evaluates himself (self evaluation) and then his/her partner (external evaluation). The analysis is carried out on the scales "social response", "dominance", "control”, "underlying mood" and "permeability".

The method used adult, heterosexual couples as a standard and enabled the description of individual characteristics, the comparison of these descriptions for both partners, and the comparison of interactions (degree of symmetry, degree of complementarity, degree of validation, the contradictions uncovered in the self and external evaluations, and the degree of identification). Couple types have not been allocated due to their controversial status (Kubinger et al., 2003).

\section{The Partnership Supply and Demand Questionnaire}

In the partnership supply and demand questionnaire each partner is able to use the Q-sort method to state which aspects of living together in the partnership, which they receive from the other partner, are particularly important to them, and which aspects they are willing to give. By using the Q-sort technique, in which individual answers must be ordered in a graded series of categories of subjective importance, the grading of every answer as "very important" is avoided and an individual ranking of priorities becomes necessary. The analysis is carried out descriptively in an overview of the interindividual and intraindividual differences between supply and demand.

In order to avoid gathering redundant information with the psychological assessment and the first interview, special attention was paid to choosing instruments to use in the study which provide information that went beyond a medical history. The purpose of the methods used was to elicit more information than the first and second interviews normally yielded, and to deliver relevant results for the assessment of the relationship. Projective methods were avoided because of the possible obstructive effects on a clear delineation between intervention and assessment. The Giessen Test and The Partnership Supply and Demand Questionnaire were chosen, on the one hand, because they were specially designed for use with couples (as opposed to many other methods which provide more insight into relationships between more than two people), and also because they offer many opportunities for couples therapy feedback. They could positively influence the therapy process by providing both more information to the therapist and more clarity to the client, and they therefore have the potential to focus the therapeutic process and steer it onto the right tracks.

The results of the questionnaire were compiled by the person in charge of the study and retained in one closed envelope for the therapist and another for the client. During the first session that the client and therapist had together the envelopes were opened and the results were read. The other trial group sessions of the study took place in a similar manner to those of the control group (again see Figure 1).

\section{Gathering of Data}

The gathering of data at the Institut für Ehe-und Familien- therapie ran from April 2006 (first applications) to August 2007 (last results from the couples in the study).

\section{The Participants}

The couples who took part in the study consisted of 42 men and 42 women. At the time of initial contact 23 couples (54.8\%) were married and 19 (45.2\%) were living together. $73.8 \%$ of the clients stated that they lived with their partner and one or more children, $14.3 \%$ lived with their partner, 9.5\% lived alone and $2.4 \%$ lived alone with their child. It was not possible to collect information about the current professions of 12 of the 84 people in the study. Of the remaining 72 people, 40 were employees $(55.6 \%), 10$ stayed at home $(13.9 \%), 6$ were unemployed (8.3\%), 5 were students, 4 (5.6\%) were self employed and 3 (4.2\%) were skilled workers. 3 people were retired. The couples who contacted the Institut für Ehe-und Familientherapie for therapy all came from the greater Vienna area.

\section{Application}

25 couples (59.5\%) made contact seeking therapy of their own initiative, the other 17 couples (40.5\%) were referred (for example by counseling centres, psychiatric institutions, etc.). In $66.7 \%$ of cases, contact was made by the woman.

17 couples (40.5\%) gave a possible separation as their reason for the application, 23 couples (54.8\%) indicated conflict within the relationship, and for two couples (4.8\%) violence was the reason for starting therapy.

\section{The Setting}

13 couples had a male therapist, 21 couples a female therapist, 2 couples had a male/female co-therapist team, and 2 couples a female/female co-therapist team. 4 couples, who had had an assessment appointment, did not start therapy at the IEF.

\section{Procedure}

There was room in the study for 42 couples, i.e. 84 individuals. There were 26 couples $(61.9 \%)$ in the trial group and 16 (38.1\%) in the control group. The clients included in the study contacted the IEF about couple therapy by phone and had a 50:50 chance of being assigned either to the trial or control group. When the clients made contact by phone a list immediately identified if they were to be in groups with or without Psychological Assessment. The clients with psychological assessment were immediately invited to the first assessment appointment. Every client, regardless of whether they were assigned to the trial group or control group was informed that there would be a waiting period before the first interview. The waiting period at the Family Therapy Institute is, several weeks to months due to the high demand, and this means that by the time a first interview session becomes available the client may possibly have lost interest in therapy or have solved their own problems themselves.

It is notable that considerably more clients from the trial group actually appeared for their first interview, although they had exactly the same length of time to wait for the first interview. This explains the difference in percentage of clients in the trial group and control group after distribution. 


\section{Results}

\section{Therapy Status}

In August 2007, 21 couples (50.0\%) were in ongoing therapy according to study conditions, 17 (40.5\%) had ended therapy, 3 were no longer interested and one couple remained on the waiting list. $56.0 \%$ of the couples for whom therapy had already ended belonged to the group without assessment (control group) and $44.0 \%$ to the group with assessment (trial group) (see Table 1). As regards the completion or continuation of therapy, there was no significant difference (chi-square test: $\mathrm{p}=$ 0.444 ) between the couples with and the couples without psychological assessment.

Of the 17 couples who were no longer in therapy, 8 (41.1\%) had broken off the therapy, 9 (52.9\%) had ended the therapy in mutual agreement with the therapist or therapists. Also in this case, there was no significant difference regarding the reasons for ending therapy between the two groups (chi-square test: $\mathrm{p}=$ 0.819 , see Table 2 ).

\section{Duration of the Therapy}

The number of clients in therapy over the four observed sessions can be found in Figure 2. Of 26 (100\%) clients starting therapy with psychological assessment, 22 (84.6\%) appeared for the first therapy session. The same number of clients with psychological assessment came to the second session. 20 (76.9\%) continued with the third session, and there was a total of 19 present at the fourth session (73.1\%). The distribution of clients without psychological assessment looked a little different.

In this case, 16 couples appeared for the first session (the $100 \%$ mentioned in the table should not disguise the fact that considerably more couples made contact and underwent a first interview appointment. However, as they were part of the group without assessment they were not considered to have not appeared for their first session - a situation that will be explored at more length in the discussion). $87.5 \%$ (14 couples) were at the second session, $68.8 \%$ at the third and only $50.0 \%$ (8 couples) remained for the fourth session. The difference in number of sessions attended between the couples with and without psychological assessment was not significant (chi-square test: $\mathrm{p}=$ 0.075).

Table 1.

Therapy status.

\begin{tabular}{lll}
\hline & Ongoing Therapy & Ended Therapy \\
\hline $\begin{array}{l}\text { With Psychological } \\
\text { Assessment }\end{array}$ & $14(56.0 \%)$ & $11(44.0 \%)$ \\
$\begin{array}{l}\text { Without Psychological } \\
\text { Assessment }\end{array}$ & $7(43.8 \%)$ & $9(56.3 \%)$ \\
\hline
\end{tabular}

Table 2.

Reasons for ending therapy.

\begin{tabular}{lll}
\hline & Couple Drop Out & $\begin{array}{l}\text { Mutually Agreed } \\
\text { Cessation }\end{array}$ \\
\hline $\begin{array}{l}\text { With Psychological } \\
\text { Assessment }\end{array}$ & $4(50.0 \%)$ & $4(50.0 \%)$ \\
$\begin{array}{l}\text { Without Psychological } \\
\text { Assessment }\end{array}$ & $4(44.4 \%)$ & $5(55.6 \%)$ \\
\hline
\end{tabular}

The time between application and first session was different between the two groups: 69 days (range: 21-138) versus 52 days (6-187), for the trial group and control group respectively. Whereas the time period within the trial group between application and testing was about 30 days (12-62). As regards the time period between the individual sessions, there was no significant difference between the control group and trial group couples (GLM: $\mathrm{p}=0.418$ ).

\section{Therapeutic Progress Made Over the Course of the Sessions}

\section{Self Evaluation by the Clients}

The self evaluation of therapeutic success of the clients with and without psychological assessment is recorded in Table 3. The evaluation of the therapeutic progress of clients in the group with psychological assessment shows a significant difference between the different points in time in the therapy (Friedman test, $\mathrm{p}=0.002$ ). The self evaluation increased constantly over time. The group without psychological assessment also displayed a significant difference between points in time (Friedman test, $p=0.005$ ). After an initial increase in self evaluation, by the 3rd session this had fallen below the value for the first session, only to increase significantly again in the fourth session. For clients with psychological assessment significantly better values, in comparison to the first session, were already apparent by the third session, for clients without assessment this improvement was not apparent until the fourth session.

If the difference in self evaluation between the sessions in the categories, improvement (“+”), no improvement (“0”) and deterioration ("-") is considered, it becomes apparent that between the 2nd and 3rd sessions significant frequent improvements appear in the group with psychological assessment, while significant frequent improvements only become clearly apparent in the group without psychological assessment between the 3rd and 4th sessions (Table 4). When observed in detail the improvements both at the time point of session 3 and 4 are significantly higher for the group with psychological assessment.

A breakdown of the results according to gender shows that there is no difference in self evaluation for men over time between the groups with and without psychological assessment (Friedman test; $p=0.069$ ). Only in the third session was a significant difference to be seen ( $U$ test; $p=0.047$ ), in that male

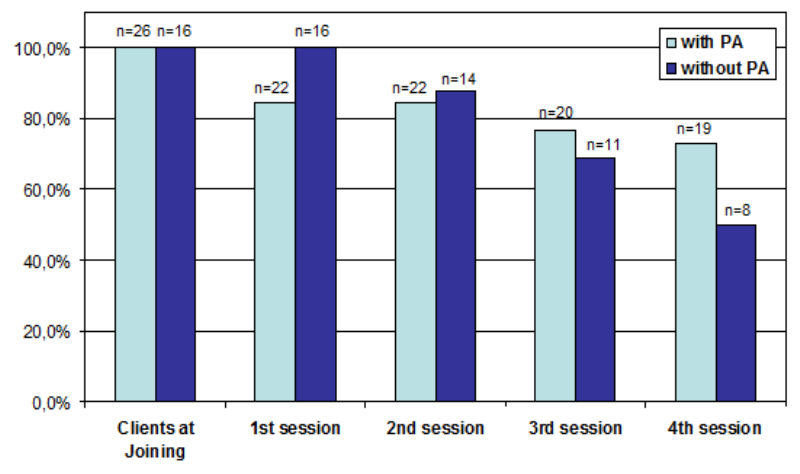

Figure 2.

Number of clients in therapy. $(P A=$ Psychological Assessment $)$ 
Table 3.

Evaluation of therapeutic goals with and without psychological assessment.

\begin{tabular}{llcll}
\hline & \multicolumn{1}{c}{$\begin{array}{c}\text { With Psychological } \\
\text { Assessment }\end{array}$} & \multicolumn{1}{c}{$\begin{array}{c}\text { Without Psychological } \\
\text { Assessment }\end{array}$} \\
\hline Self Evaluation & $\mathrm{n}$ & Md (range) & $\mathrm{n}$ & Md (range) \\
1st session & 40 & $4(0-10)$ & 30 & $5(1-10)$ \\
2nd session & 39 & $5(0-10)$ & 24 & $6.5(2-10)$ \\
3rd session & 36 & $6.5(3-10)$ & 17 & $5(0-10)$ \\
4th session & 28 & $6.5(3-10)$ & 11 & $8(4-10)$ \\
\hline
\end{tabular}

Table 4.

Evaluation of therapeutic goals with and without psychological assessment, including differences in self evaluation between sessions.

\begin{tabular}{lllll}
\hline & $\begin{array}{c}\text { With Psychological } \\
\text { Assessment }\end{array}$ & $\begin{array}{c}\text { Without Psychological } \\
\text { Assessment }\end{array}$ \\
\hline Self Evaluation & $\mathrm{n}$ & Md (range)/\% & $\mathrm{n}$ & Md (range)/\% \\
\hline 1st session & 40 & $4(0-10)$ & 30 & $5(1-10)$ \\
\hline Difference & + & $21(56.8 \%)$ & + & $12(50.0 \%)$ \\
1st-2nd session & 0 & $6(16.2 \%)$ & 0 & $\begin{array}{l}6(25.0 \%) \\
6(25.0 \%)\end{array}$ \\
\hline 2nd session & 39 & $5(0-10)$ & 24 & $6.5(2-10)$ \\
\hline Difference & + & $22(66.7 \%)$ & + & $4(26.7 \%)$ \\
2nd-3rd session & 0 & $4(12.1 \%)$ & 0 & $3(20.0 \%)$ \\
\hline 3rd session & - & $7(21.2 \%)$ & - & $8(53.3 \%)$ \\
\hline Difference & 36 & $6.5(3-10)$ & 17 & $50-10)$ \\
3rd-4th & 0 & $10(35.7 \%)$ & + & $8(88.9 \%)$ \\
session & - & $11(39.3 \%)$ & - & $0(0.0 \%)$ \\
\hline 4th session & 28 & $6.5(3-10)$ & 11 & $8(4-10)$ \\
\hline
\end{tabular}

(+. improvement, 0. no change, -. decrease)

clients with psychological assessment evaluated their therapeutic progress as being better (Med $=6.5$ ) than men without assessment (Med $=4.5)$. In the case of the women a significant difference over time (Friedman test: $p=0.039$ ) was observed in the group with assessment which was not present in the group without psychological assessment (Friedman test, $\mathrm{p}=0.115$ ).

Women with assessment improved continually over time in their self evaluations (Med. 1st session $=4.5$; 2nd session $=5$; 3rd session $=6.5$; 4 th session $=7$ ). Women without assessment displayed a non significant decline after the third session (Med. for the 4th sessions: $5,6,5,8$ ).

\section{External Evaluation by the Therapist}

Clients from the group with psychological assessment always gave themselves a higher value than the therapist did. By the 3rd session this difference had become significant (Wilcoxon test, $\mathrm{p}<0.001$ ) (Table 5). The clients without psychological assessment evaluate their therapeutic progress higher than their therapists do. In this group the difference becomes significant in the 1 st session (Wilcoxon test, $\mathrm{p}=0.003$ ) and 2 nd session (Wilcoxon test, $\mathrm{p}=0.002$ ) (Table 5). There was no significant difference in the therapist's evaluations between clients wi- th/without psychological assessment (U test, $\mathrm{p}>0.05$ ).

\section{Subjective Evaluation of Psychological Assessment}

By the Clients: $66.7 \%$ of clients stated that the examination prompted them to think things through and 33.3\% felt the psychological test helped them to deal with their difficulties. By the Therapists: In only $10.8 \%$ of cases did the therapists experience psychological assessment as being supportive of the therapeutic process. In at least $24.3 \%$ of cases the results were considered a relevant source of additional information. In their evaluation of the benefits of the assessment for the clients, the therapists indicated that they believed psychological assessment had prompted the client to think things through in only $25.7 \%$ of cases, and it was accepted that assessment helped clients to deal with their difficulties in only $8.6 \%$ of cases.

\section{Discussion}

The results of this study relating to the effects of psychological assessment on the therapeutic process show that psychological assessment doesn't have a negative effect on any of the parameters investigated by us. The values of the self evaluation of therapeutic success increase over time for clients with and without assessment - a fact that indicates that therapy is experienced by clients as helpful and relevant irrespective of the provision of psychological assessment or its absence. It is noticeable, however, that for clients with psychological assessment the therapeutic benefits subjectively experienced seem to occur sooner and may be more permanent. An earlier significant improvement is experienced by the clients in this study, i.e. after the completion of testing, and this improvement is more stable. A clear difference between the genders regarding benefit from psychological assessment could not be established. It was notable that the therapeutic progress experienced by the clients was always greater than that of their therapists' evaluations. The therapists did, however, see a continual improvement in their clients, but indicated obvious therapeutic progress only at a later stage than the clients did. The earlier and more stable therapeutic success for clients with psychological assessment was related, as also stated by the clients who were questioned about the subjective evaluation of the assessment carried out, to the examination with psychological testing of the couples being useful in helping the couples to deal with the problems that had led them to therapy in the first place. They could therefore make earlier constructive use of the therapy. The initial conclusion to be drawn is that, despite the clearly very limited context

Table 5.

Evaluation of therapeutic success by the therapist (treatment and control group).

\begin{tabular}{lccll}
\hline & \multicolumn{2}{c}{$\begin{array}{c}\text { With Psychological } \\
\text { Assessment }\end{array}$} & \multicolumn{2}{c}{$\begin{array}{c}\text { Without Psychological } \\
\text { Assessment }\end{array}$} \\
\hline Self Evaluation & $\mathrm{n}$ & Md (range) & $\mathrm{n}$ & Md (range) \\
1st session & 41 & $4(0-7)$ & 28 & $3(1-7)$ \\
2nd session & 39 & $4(0.8)$ & 22 & $3(1-6)$ \\
3rd session & 36 & $4(1-9)$ & 15 & $4(0-7)$ \\
4th session & 19 & $6(2-9)$ & 9 & $6(4-8)$ \\
\hline
\end{tabular}


of only two instruments being used in the psychological test examination within the unique circumstance of couples therapy within the framework of a systemic therapy institute, psychological assessment can indeed have a very positive influence on the therapeutic process. A further positive aspect of psychological assessment is apparent in that an assessment done before the first session can lead to a couple appearing for therapy despite a long waiting period. It must be noted that there is no data about how many couples without assessment dropped out during the waiting period, as it is exclusively the couples who appeared for their first interview appointment in the group without assessment who appear in the statistics. At this point therefore it can only be observed, without being supported by figures, that the number of couples that did not appear for their first interview after assessment was carried out was an order of magnitude smaller than that of the couples in the group without an assessment appointment. It seems possible that either this difference can be explained by the couples having already "invested" in the assessment and wanting to justify having gone to this trouble and they therefore appear for their first interview to find out the results of the assessment, or it could be that the assessment carried out during the waiting period conveyed the impression to the couples that real interest was being shown in their problems and in this way a stable commitment to the therapy institute was established. The fact that there is no difference between the groups in the breaking off or ending of therapy indicates that the couples who appeared for therapy, irrespective of whether testing has previously been carried out or not, were genuinely interested in undertaking therapy.

In order to answer the question of what use psychological assessment has for clients and therapists at the end of the day, the subjective evaluation of the relevance of psychological assessment was investigated from a clients' and therapists' point of view. The final evaluation questionnaire filled out by the trial group included the opportunity to give an open answer to the question, "I found the questionnaire examination to be helpful/not helpful, because:” While the clients were sparing with their criticism, and only in one or two cases said that the test results were not of enough significance or already known, the therapists took issue with numerous difficulties with psychological assessment. The criticism included the statements that psychological assessment was too superficial, irrelevant to the therapeutic process, would cement hypotheses, and that the results were in stark contrast to the problems claimed. Not one therapist gave a positive evaluation of psychological assessment. The clients, on the other hand, presented a great many arguments in support of psychological testing. The clients indicated that they found the questionnaire examination to be helpful since it gave them an overview of the necessity of formulating their difficulties and general problems, concretized the "initial conditions" of the problems, provoked contemplation of and engagement with their image of themselves and how others saw them, and in this way allowed the development of a new understanding of the problem. The clients noted that in addition to this they had gained new perspectives on their problems, but also the things they had in common had become clearer and avenues to discussion between the partners had opened up. It is certainly necessary and desirable that further investigation, using various different control studies and different test techniques, is carried out in order to identify the optimal ways of implementing psychological assessment within the therapeutic process for the future. This first study regarding the possibility, not simply of the coexistence, but the actual alliance of psychological assessment and psychotherapy has clearly shown that this course of action is worth pursuing.

\section{Acknowledgements}

The authors would like to thank the head of the Institute für Ehe-und Familientherapie, Dr. Joachim Hinsch, and his team who made this study possible.

\section{References}

Austrian Psychotherapy Act. http://www.psyonline.at

Beckmann, D., Brähler, E., \& Richter, H. E. (1983). Der Gießen-test, (3rd Edition). Bern: Verlag Hans Huber.

Benninghoven, D., Cierpka, M., \& Thomas, V (2003). Überblick über familiendiagnostische fragenbogeninventare. In: M. Cierpka (Ed.), Handbuch der Familiendiagnostik (pp. 487-510). Berlin: Springer.

Braun, U., \& Regli, G. (2000). Psychotherapie-evaluation in der praxis. In: A. R. Laireiter (Ed.), Diagnostik in der Psychotherapie (pp. 459475). Vienna: Springer.

Brähler, E., \& Brähler, C. (1997). Paardiagnostik mit dem Gießen-test. Bern: Verlag Hans Huber.

Cierpka, M. (2000). Diagnostik in der familientherapie. In: A. R. Laireiter (Ed.), Diagnostik in der psychotherapie (pp. 217-234). Vienna: Springer.

Cierpka, M. (2003). Handbuch der familiendiagnostik. Berlin: Springer.

Cierpka, M., \& Frevert, G. (1994). Die Familienbögen. Göttingen: Hogrefe.

Fiegl, J., \& Reznicek, E. (2000). Diagnostik in der systemischen therapie. In: A. R. Laireiter (Ed.), Diagnostik in der psychotherapie (pp. 235-245). Vienna: Springer.

Gehring, T. M. (1998). Familiensystemtest. Weinheim: Beltz.

Howells, J. G., \& Lickorish, J. R. (1989). Familien-Beziehungs-test (4th Edition). Munich: Reinhard.

Kos, M., \& Biermann, G. (2002). Die verzauberte familie (5th Edition). Göttingen: Hogrefe, Göttingen.

Kubinger, K. D. (2006). Psychologische diagnostik - theorie und praxis psychologischen diagnostizieren. Göttingen: Hogrefe.

Kubinger, K. D. (2007). Belastendes partnerwahlmuster oder versagter partnerwunsch: Rehabilitationsansätze durch den fragebogen zu angebot und nachfrage in partnerschaften. In B. Ahrbeck \& E. V. Kardoff (Eds.), Die fragile dynamik der psyche als risiko und chance in der rehabilitation (pp. 38-49). Achen: Shaker.

Kubinger, K. D., Alexandrowicz, R., Punter, J. F., \&. Brähler, E. (2003). Paardiagnostik mit dem Gießen-test-typische paarprofile in der “normal”-bevölkerung. Familendynamik, 28,. 219-235.

Kubinger, K. D., \& Jäger, R. S. (2003). Schlüsselbegriffe der Psychologischen Diagnostik. Weinheim: Beltz PVU.

Laireiter, A. R. (2000a). Diagnostik in der psychotherapie. Vienna: Springer.

Laireiter, A. R. (2000b). Diagnostik, dokumentation und qualitätssicherung von Psychotherapie. In: Laireiter, A. R. (Ed.), Diagnostik in der psychotherapie (pp. 441-458). Vienna: Springer.

Laireiter, A. R. (2000c). Diagnostik in der psychotherapie: perspektiven, aufgaben und qualitätskriterien. In: A. R. Laireiter (Ed.), Diagnostik in der psychotherapie (pp. 3-23). Vienna: SpringerVerlag.

Laireiter, A. R. (2005). Klinisch-psychologische und psychotherapeutische diagnostik. In: H. Bartuska et al. (Eds.), Psychotherapeutische diagnostik (pp. 199-226). Vienna: Springer. doi:10.1007/3-211-29398-1_25

Ludewig, K. (2005). Einführung in die theoretischen grundlagen der systemischen therapie. Heidelberg: Carl-Auer-Systeme Verlag. 
Mattejat, F. (1994). Das subjektive familienbild. Göttingen: Hogrefe.

Orlinsky, D. (2008). Die nächsten 10 Jahre psychotherapieforschung. eine kritik des herrschenden Forschungsparadigmas mit korrekturvorschlägen. Psychother Psych Med, 58, 345-354.

doi:10.1055/s-2008-1067444

Pfundner, M. (1997). Erwartungen an die partnerschaft. Erhebung der determinanten eines wunschbildes mittels des fragebogens FEP. Degree Dissertation, Vienna University.

Remschmidt, H., \& Mattejat, F. (1999). Familien-identifikations-test. Göttingen: Hogrefe.

Scheib, P., \& Wirsching, M. (1994). Diagnostik in der familientherapie. In: P. L. Janssen \& W. Schneider (Eds.), Diagnostik in psychotherapie und psychosomatik (pp. 165-195). München: Urban \& Fischer.

Simader-Hunek, N. (2004). Die praktische bewährung des "Frage- bogens zu Angebot und Nachfrage in partnerschaften" (FAN): Was teenager heute geben und haben wollen. Degree Dissertation, Vienna University.

Stieger, C. (1995). Paardiagnostik in der systemischen therapie entwicklung eines praktikerfreundlichen, hierarchischen und integrativen Diagnoseschemas zur einschätzung von paarsystemen. Degree Dissertation, Vienna University.

Thomas, V. (2003). Prozessmodelle und ratingskalen. In: M. Cierpka, (Ed.), Handbuch der familiendiagnostik (pp. 469-485). Berlin: Springer.

Training guidelines - Psychoanalysis (Arbeitskreis Psychoanalyse). http://www.neumeister.info/Prospekt\%20Grazer\%20Sektion.pdf

Training guidelines - Systemic Therapie (Lehranstalt für Systemische Familientherapie). http://www.la-sf.at/ 